\title{
Analysis of Factors Influencing Audit Quality based on Grounded Theory Methods
}

\author{
Ziyi Zhou \\ School of Business and Tourism Management, Yunnan University, Kunming, China \\ 1987575@dingtalk.com
}

\begin{abstract}
With the gradual increase in business diversity and the increase in the degree of informatization of various industries, the level of audit quality has brought a great impact. This article collects 6 cases of my country's supervision and control commission penalties from 2010 to 2020, and adopts grounded theory methods to study the factors affecting audit quality and draw conclusions. The analysis first further summarizes the initial categories obtained from the analysis into the main categories, and then refines the core categories based on the logical relationship between the main categories. On this basis, it proposes ways to improve audit quality. factor.
\end{abstract}

Keywords: Grounded Theory; Audit Quality; Case Analysis.

\section{Introduction}

\subsection{Significant of the Subjects}

In the Internet age, the degree of informatization in companies in various industries and fields is getting higher and higher. Although such changes have gradually changed the company's financial processing procedures, it has brought challenges to the auditing business of accounting firms. For example, due to the lack of information technology capabilities of the auditors, there is a great risk of failure in the audit of the effectiveness of the system. In this way, it will also have a certain impact on the quality of the audit report.

\subsection{Overview of Research Status at Home and Abroad}

From the perspective of time, foreign scholars began to study the related theories of audit quality and audit quality control. The beginning time was earlier than the time when Chinese scholars began to study. Therefore, Chinese scholars are involved in audit quality and audit quality control. A large part of the theoretical basic research is based on the research content of foreign scholars. In recent years, domestic and foreign related research documents have been abundant on the reasons that affect audit quality control. Different scholars have adopted different perspectives and used various methods to analyze and study the factors that affect audit quality control. However, there are few studies that combine the Internet background with the influencing factors of audit quality and adopt grounded theory, which has become a blank point in audit quality research.

\subsection{Research Methods}

This article intends to use grounded theory and case analysis method combined research method for research.

(1) Grounded theory. This theory requires researchers to adopt the standard of "theoretical sampling", select research objects purposefully, sort out and analyze the original data obtained, and finally generate and test the theory. Therefore, this article uses grounded theoretical research methods to construct a theoretical model of factors affecting audit quality.

(2) Case analysis method. The case analysis method is to study and analyze the problems that arise in the actual execution of the audit business as a case, and analyze representative and typical cases to draw general conclusions that are beneficial to the development of the industry. In this article, the main part of the audit failure of a number of domestic accounting firms, through online literature review and other forms of data collected for inductive analysis, and put forward the problems in the 
audit quality control in actual business. From both internal and external aspects, suggestions for improvement are given, and the research conclusions of this article are draw.

\section{Grounded Theory}

Grounded Theory (GT) is a qualitative research method whose main purpose is to establish a theory based on empirical data (Strauss, 1987: 5). Researchers generally do not have theoretical hypotheses before the start of the research, and start directly from actual observations, sum up empirical generalizations from the original data, and then rise to the systematic theory. This is a method of establishing a substantive theory from the bottom up, that is, on the basis of systematically collecting data, looking for core concepts that reflect the nature of things and phenomena, and then constructing relevant social theories through the connections between these concepts. Grounded theory must be supported by empirical evidence, but its main feature is not in its empirical nature, but in that it abstracts new concepts and ideas from empirical facts. In philosophical thinking, the grounded theoretical approach is based on the post-positivist paradigm, emphasizing the falsification of established theories.

\section{Case Analysis}

\subsection{Data Selection}

This article selects 6 audit failure cases that have a greater impact on the penalties of the China Securities Regulatory Bureau-Key Bridge Communications, Asia Pacific Industry, Zhenlong Specialty Products, Huaze Cobalt Nickel, Zero Seven Stocks, and Kangdexin. The originals were collected and sorted through multiple channels. data.

The source of the information is the China Securities Regulatory Commission's Management Information Catalog.

\subsection{Data Analysis}

\subsubsection{Open Coding}

Table 1. Examples of open coding

\begin{tabular}{|c|c|c|}
\hline coding & concept & Initial category \\
\hline \multirow{2}{*}{ A1 } & Auditors did not implement & \multirow{2}{*}{ Invalid audit procedure } \\
\hline & Alternative procedure is invalid & \\
\hline \multirow{3}{*}{$\mathbf{A} 2$} & No further procedures & \multirow{3}{*}{ Missing audit procedures } \\
\hline & Missing alternative audit procedures & \\
\hline & Insufficient audit procedures & \\
\hline \multirow{2}{*}{ A3 } & Lack of qualifications for auditors & \multirow{2}{*}{ Insufficient professional competence } \\
\hline & No sensitivity & \\
\hline \multirow{2}{*}{ A4 } & Did not fill in on time & \multirow{2}{*}{ Incomplete working paper } \\
\hline & Did not submit on time & \\
\hline A5 & $\begin{array}{l}\text { The auditor did not implement the } \\
\text { corresponding procedures }\end{array}$ & $\begin{array}{l}\text { Insufficient understanding of the audited entity } \\
\text { and the environment }\end{array}$ \\
\hline
\end{tabular}


Open coding is a process of decomposing a variety of collected data one by one, and constantly comparing the similarities and differences between the phenomena reflected in the data, and then labeling the phenomena to conceptualize and categorize them. In this process, it is necessary to constantly ask questions, compare the similarities and differences of the data, and conduct theoretical sampling based on the gradually emerging concepts and categories, and further collect data, and then further the new data and the original data and the refined concepts and categories. The comparison leads to the development of the main categories.

\subsubsection{Spindle Coding}

The main axis coding is based on the relevance of the initial categories obtained by the open coding. It only conducts in-depth analysis on one category at a time through clustering, and finds the correlation around this category, so it is called the "axis "The main task is to discover and establish potential logical connections between categories.

According to the relevance between the initial categories obtained by the open coding, it is further summarized, and only one category is analyzed in depth through clustering.

Table 2. Examples of initial categories and main categories

\begin{tabular}{|c|c|}
\hline Initial category & Main category \\
\hline A1 Invalid audit procedure & \multirow{3}{*}{$\begin{array}{l}\text { B1 Insufficient professional competence of } \\
\text { auditors }\end{array}$} \\
\hline A2 Missing audit procedures & \\
\hline A3 Insufficient professional competence & \\
\hline A4 Incomplete working paper & B2 Incomplete working paper \\
\hline $\begin{array}{l}\text { A5 Insufficient understanding of the audited entity and } \\
\text { the environment }\end{array}$ & $\begin{array}{c}\text { B3 Insufficient understanding of the audited unit } \\
\text { environment }\end{array}$ \\
\hline
\end{tabular}

\subsubsection{Selective Coding}

Selective coding means that after systematic analysis of all the conceptual categories that have been found, a "core category" that plays a role as an outline guide is selected, and all other categories are combined into a whole and then further analyzed. Condensed a more abstract core category. There are two ways of selective encoding its:

The first is to divide the core categories according to the logic of "causal conditions-phenomenacontext-intermediary conditions-action strategies-results"; the second is to refine the core categories based on the logical relationship between the main categories. Because the logical relationship between the main categories involved in this article is clear, it is more appropriate to divide the core categories in the second way.

After systematic analysis of all the conceptual categories that have been found, a "core category" that plays the role of outline and guidance is selected.

Table 3. The core categories of selective coding

\begin{tabular}{|c|c|}
\hline Core category & Main category \\
\hline Professional competence & B1 Insufficient professional competence of auditors \\
\hline Working papers & B2 Incomplete working paper \\
\hline Business execution & B3 Insufficient understanding of the audited unit environment \\
\hline \multicolumn{2}{|c}{} \\
\hline
\end{tabular}




\section{Conclusions and Recommendations}

\subsection{Conclusion}

Business work papers, business execution, professional competence, monitoring and customer relationships are the key factors affecting audit quality.

\subsection{Suggestions}

\subsubsection{Improve the Management of Working Papers}

Strengthening the management of internal audit work papers is conducive to the control of audit quality during the audit process. Preparation of audit work drafts Ding work runs through all links, stages, and steps of the audit process, from the initial collection of the original data of the audited unit (or project), the analysis of the original data, the acquisition of audit evidence, and the final. Therefore, by strengthening the management of the audit work papers and controlling the quality of each link of the audit process, the high-quality internal audit work of each link is reflected in the audit work papers.

\subsubsection{Strengthen the Training of Auditors' Professional Competence}

Auditing in the new era must focus on solving the contradictions of diversified economic development, wide audit coverage, outdated audit concepts, old methods, and uneven allocation of audit resources. To expand the coverage of computer audit through informatization, digitization, and big data comparison and analysis, to require resources from informatization and efficiency from big data, and to focus on improving the ability of big data auditing. It is necessary to change the old and rigid thinking of the past, work in accordance with the rules, solidify the thinking mode, copy, and copy, and report the same inertial mode.

\subsubsection{Standardize the Execution Process of the Business}

In the process of business execution, it is necessary to pay attention to review procedures, implement review systems, clarify the authority of each person, define the internal audit procedures of the project team and the responsibilities of external review personnel, and keep work records, control at all levels, and report problems in time, and There is evidence to follow.

\section{References}

[1] Wang Cuilin, Li Wen. An analysis of audit quality influencing factors based on grounded theory--Taking Ruihua Firm as an example [J]. Finance and Accounting Monthly, 2020(24): 86-92.

[2] Li Xiaoqing, Li Binglian, He Weixuan, Zhou Jian. The formation path of enterprise digital innovation based on grounded theory--multi-case study[J/OL]. Technological progress and countermeasures:1-9. http: //kns.cnki.net/kcms/detail/42.1224.G3.20210615.1035.028.html.

[3] Meng Meng, Zhu Qinghua. Research on Influencing Factors of Mobile Visual Search User Experience Based on Grounded Theory[J]. Modern Information, 2021, 41(06): 97-107.

[4] Zhu Xiangping. Case analysis of IPO financial fraud based on grounded theory[J]. Finance and Accounting Newsletter, 2021(04):116-119.

[5] Díaz Crescitelli Matías Eduardo, Hayter Mark, Artioli Giovanna, Sarli Leopoldo, Ghirotto Luca. Relational dynamics involved in therapeutic discordance among prescribers and patients: A Grounded Theory study.[J]. Patient education and counseling,2021. 